\title{
SIMULATION-BASED EVALUATION OF FUEL CONSUMPTION IN HEAVY CONSTRUCTION PROJECTS BY MONITORING EQUIPMENT IDLE TIMES
}

\author{
Reza Akhavian \\ Amir H. Behzadan \\ University of Central Florida \\ 4000 Central Florida Blvd. \\ Orlando, FL 32816-2450, USA
}

\begin{abstract}
A systematic approach to idle time reduction can significantly boost the efficiency of construction equipment during their lifetime, result in higher overall productivity, and ultimately protect public health and the environment. Towards this goal, this paper describes research aimed at designing a framework for estimating heavy equipment idle times during a construction project. A distributed sensor network is deployed to communicate and present metrics about idle times and production rates and inform project managers and field operators when idle time thresholds are exceeded. The designed user interface includes a graphical representation of the site layout to visualize the status of equipment in real time in support of project management and decision-making tasks. Collected data will be also used to determine energy consumption and $\mathrm{CO}_{2}$ emission levels as the project makes progress. Using simulation modeling, various operational strategies are evaluated from the point of view of equipment emission and idle times.
\end{abstract}

\section{INTRODUCTION}

According to the Environmental Protection Agency (EPA), construction industry is ranked third just behind the "oil and gas" and the "chemical manufacturing" sectors in terms of contributing to greenhouse gas (GHG) emission (EPA 2008). Extensive use of energy-intensive equipment, in particular, produces high levels of emission. EPA states that if diesel fuel consumption reduces by only $10 \%, \mathrm{CO}_{2}$ emission will decrease by 14.8 million pounds or approximately $5 \%$ of the entire energy consumption in the construction sector (EPA 2009). Construction equipment typically use diesel to produce power for base engine and are considered major sources of nonroad air pollution (Lewis et al. 2009). They emit huge amounts of nitrogen oxides (NOx), carbon monoxide (CO), particulate matter (PM), and hydrocarbons (HC). In 2002, NOx, CO, and PM emissions from nonroad construction equipment were 7\%, 0.8\%, and $0.8 \%$ of total annual emissions in the United States, respectively (Rasdorf et al. 2010).

Ideally, construction contractors should control activities that may result in GHG emissions on a construction site. EPA categorizes the ability of construction contractors to affect activities associated with GHG emissions into three groups namely "most influence", "some influence possible", and "little influence", and lists equipment idling in the first category (EPA 2009). In addition to nonroad construction vehicles, idling is equally important for on-road long-haul truck activities because drivers have to take mandatory rest stops to meet the Federal Hours of Service (HOS) regulations (Frey et al. 2009). Using simplifying assumptions, EPA estimates that 960 million gallons of diesel fuel are annually consumed as a result of long-haul truck idling (Lim 2002). Therefore, finding methods to reduce construction equipment idling is of major significance to saving energy, environmental, and financial resources. 


\section{Akhavian and Behzadan}

EPA's construction sector strategies program report states that "... to reduce idling and the associated GHG emissions, construction firms need to evaluate when and why idling occurs in the company's activities... without data on the total idling hours for construction vehicles and equipment in the United States, the total potential emission reductions possible through sector-wide idling reductions could not be estimated ..." (EPA 2009). Therefore, obtaining a thorough knowledge of "when and why" idling occurs, not only does help design solutions to reduce idling, but also assists in regulating idling reduction practices by providing factual data on total idling hours of construction equipment. Considering all such benefits of idling reduction and the resulting energy, financial, and environmental savings, this paper describes a framework developed by authors that help estimate heavy construction equipment idle times in real time. Moreover, the user interface includes a representation of the site layout over which the latest status of equipment (reflecting busy/idle states) can be visualized using color-coding to facilitate project management and decision-making tasks, and to better communicate the results with contractors and project personnel. Also, the effect of different operational plans that can potentially impact idle times and ultimately emission rates is evaluated using discrete event simulation (DES) modeling and sensitivity analysis.

\section{PREVIOUS STUDIES}

The need for construction equipment idle time estimation for specific purposes (such as cost estimation, fuel use and emission estimation, data-driven modeling and simulation) has been highlighted in a number of recent studies (Vorster and de la Garza 1990; McCahill and Bernold 1993; Frey et al. 2008; Lewis et al. 2011; Akhavian and Behzadan 2012; Ahn and Lee 2013). However, to the best of authors' knowledge, there are very limited studies targeting the prospect of automated idling detection and idle time estimation for sustainability analysis. For example, Lewis (2009) developed a model for construction equipment emission rates in which various modes of equipment duty cycles including the idle mode accounted for different fuel use and emission rates. In another study, equipment activity durations and idle time were extracted to update a data-driven simulation model in real time (Akhavian and Behzadan 2012). Also, Peña-Mora et al. (2009) presented a framework for managing operating emissions of a construction project. The framework suggested the use of simulation methods, emission inventories, portable emissions measurement system (PEMS), global positioning system (GPS), wireless network, geographic information system (GIS), and building information modeling (BIM) for emission estimation and visualization, and also recommended corrective actions such as using biodiesel, diesel retrofit technologies, idle reduction technologies, and carbon capturing technologies. Ahn et al. (2012) used vibration signal analysis to monitor the operational status of construction equipment involved in different activity modes (working or idling). Although all such work highlighted the role of idling as one of the duty cycle modes of construction equipment that contributes to the overall equipment emission in a non-productive manner, none of the previous work in this area investigated the prospect of detecting idling instances to provide solutions for idling and emission reduction.

\section{DESCRIPTION OF THE SYSTEM}

The idle time estimation platform in this research consists of hardware peripherals and a graphical user interface (GUI). In this section, details of hardware components and the designed GUI are described.

A distributed sensor network was used to collect data from construction equipment and communicate the collected data with the GUI. Figure 1 represents a schematic illustration of the developed system. As shown in this Figure, three modes of data (i.e. position, angle, and weight) were used to determine the state of heavy equipment. For usability experiments, the positional data was collected using ultrawideband (UWB) tags mounted on equipment. With minimum modifications to the data capturing and handling algorithms, these tags can be replaced with GPS receivers for larger scale projects that cover wider operational ranges. In addition, all dump trucks were equipped with ZigBee enabled weight sensors, and attitude and heading reference system (AHRS) trackers were mounted on front-end loaders and/or excavators to capture yaw, pitch, and roll motions of their articulated parts. As a result, at any giv- 


\section{Akhavian and Behzadan}

en time, each piece of equipment could transmit a set of positional, and weight (for dump trucks) or orientation (for front-end loaders and excavators) data. This network of heterogeneous sensors provided sufficient operational data for describing the state of construction equipment and ultimately estimating idle times.

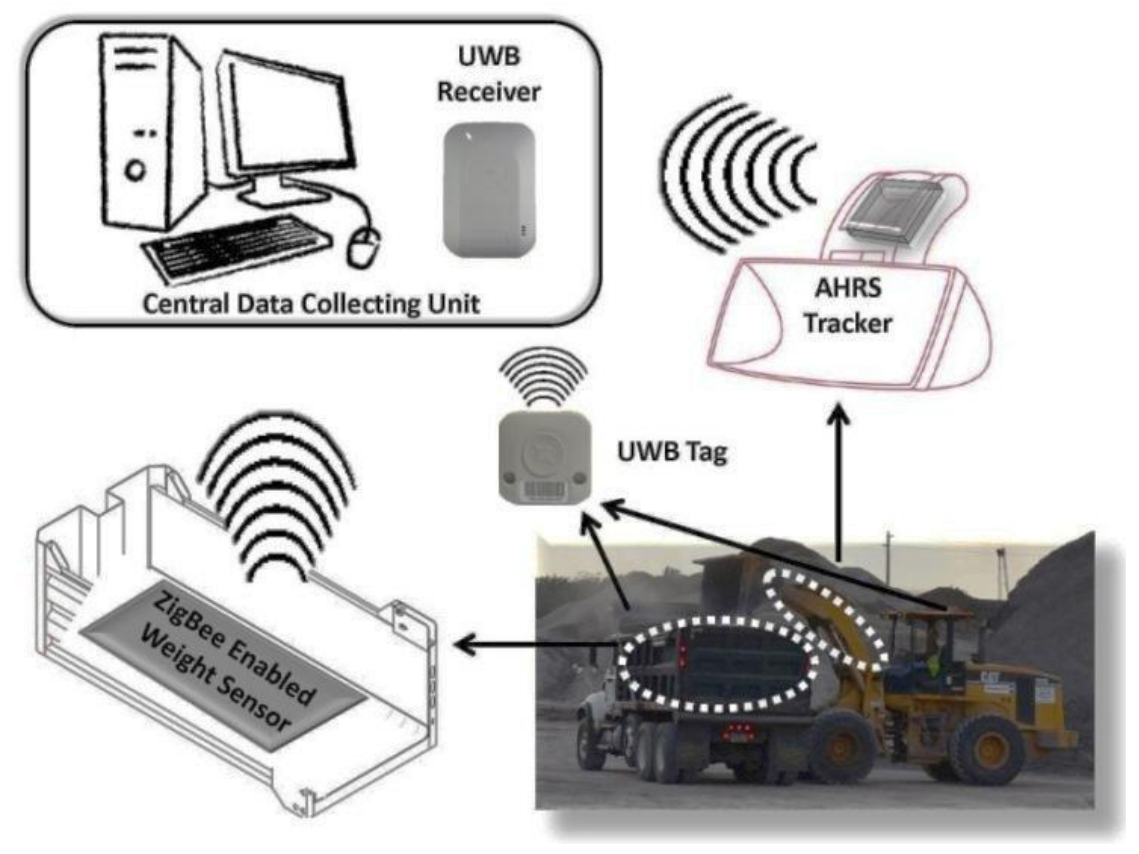

Figure 1. Schematic illustration of the sensor network used to capture states of heavy equipment.

Once the data collection process is launched, incoming time-stamped data streams from individual sensor nodes are captured and fused into a common temporal framework. Using the collected data, the binary state of each equipment described as either idle or busy is determined. In this research, idle is defined as the state of a piece of equipment at times during which it is not involved in any activity, while it should be. In other words, an idle state refers to nonproductive equipment time and a busy state refers to productive equipment time. Given these definitions, all three modes of the collected data (i.e. position, weight, and angle) contribute to extracting knowledge about the state of equipment. For example, when dump trucks wait for extended periods of time to be loaded or to dump soil, they are considered idle (i.e. nonproductive). To resolve this situation, a project manager may decide to streamline and/or optimize the resource allocation plan such that dump trucks spend less time waiting in loading and dumping queues. In fact, EPA has prescribed a limit of 30 minutes while waiting to load or unload (EPA 2006). Another example is when the equipment engine runs on idle to maintain cabin conditions for operator's comfort (e.g. air conditioning, lights). In this regard, EPA's general requirement is idling for no more than 5 minutes in any given 60 minutes (EPA 2006). As an example, a simple taxonomy-based approach to identify the binary state (idle or busy) of a dump truck in an arbitrary time window during an earthmoving operation is presented in Section 4.

\section{A SAMPLE EARTHMOVING SCENARIO}

Consider a typical earthmoving operation in which a front-end loader puts soil in a dump truck. Knowing that the dump truck is not moving, one may intuitively conclude that the dump truck is idle, whereas another logical conclusion could be that the dump truck is being loaded and thus should stay fixed in its position. In such situations, weight data can help identify an apparent idle state from an actual idle state. If a weight sensor installed on the dump truck bed shows an increasing trend in weight values while the dump 


\section{Akhavian and Behzadan}

tuck is not moving it is then clear that the dump truck is involved in an instance of loading activity and thus, cannot be considered idle. However, while the dump truck is being loaded, the front-end loader needs to scoop soil and travel with a full bucket toward the dump truck before it puts the soil into the dump truck bed. During this time, neither the position of the dump truck nor its payload is changing. Therefore, inferring that the dump truck is idle because there is no change in its position and weight is not necessarily realistic. In this case, two other pieces of information should be also considered to guarantee that the correct state is determined. First, one must check if the front-end loader is working (i.e. scooping) while the dump truck is not moving and its payload is not increasing. Second, is the question that while all of the above conditions are satisfied (dump truck is not moving, the weight is not increasing for a few seconds to few minutes, but the front-end loader is working at the same time), whether or not the dump truck is located close enough to the front-end loader (i.e. loading area). This last prerequisite is referred to as the proximity condition and if satisfied, then the logical conclusion is that the dump truck is not idle. This simple scenario highlights the complexity involved in analyzing data combinations captured from different resources, and thus justifies the need for a generic reasoning process (a.k.a data mining) to determine the exact state of the equipment. Figure 2 depicts various combinations of three data modes and trends that result in different states for a dump truck involved in an earthmoving operation.
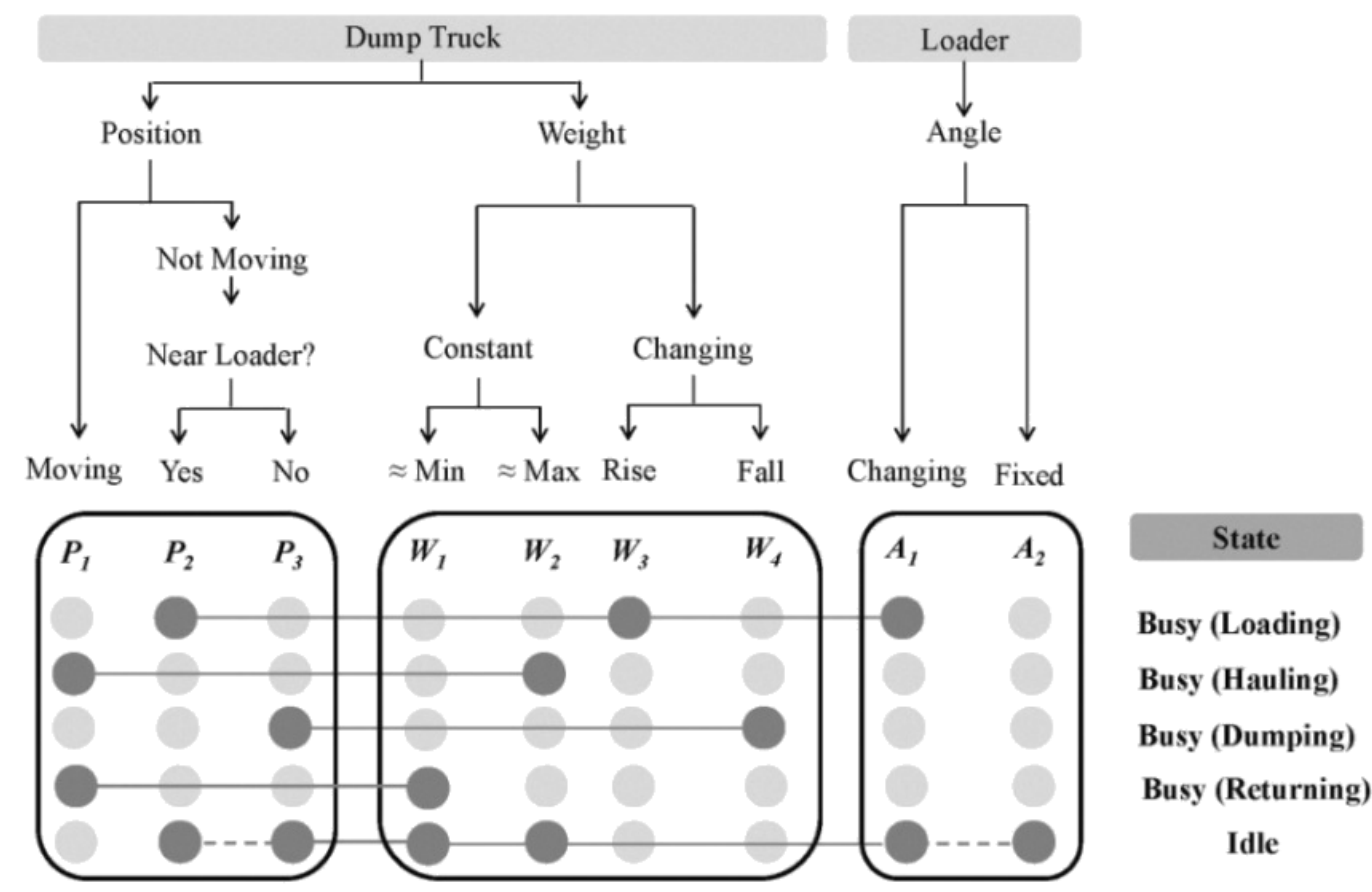

Figure 2. Taxonomy of dump truck activities in an earthmoving operation based upon multi-modal process data and operational context.

\section{GRAPHICAL USER INTERFACE (GUI) DESIGN}

The main role of the GUI is to communicate with the user and to visually notify him or her about the idle/busy state of target equipment. To be of real practical value, such notifications are sent in tow forms: (1) instantaneous idling to let the user know where/why idling occurs, and (2) overall idling when a certain threshold of cumulative idle time duration is exceeded, in accordance to definitions established by the EPA (2006). As such, a user-defined variable representing the idle time threshold for each type of equipment is introduced and instantiated, and the user will be notified if a piece of equipment is busy/idle at 


\section{Akhavian and Behzadan}

any given time, or if it has exceeded its predefined cumulative idle time threshold. In order to facilitate communication, the GUI also includes a visualized scene of the site layout over which graphical representations of the equipment involved in the operation are superimposed. The user is able to import any site layout image file and add desired pieces of equipment to the scene display. Using real time streams of positional data, 3D models of equipment are then displayed on the exact locations in the virtual scene that represent their actual positions in the real world. Also, the status of the equipment in terms of idle or busy, as well as whether each equipment has exceeded the idle time threshold are reflected on the layout by color-coding the 3D equipment models. If the equipment is "busy" it is shown in gray; if it is "idle now" it is blinking yellow, and if it "has exceeded threshold" it is blinking red and yellow. In addition to the scene representing, the site layout, and equipment models, the GUI provides the user with numerical values and indicators of the idle time, and a time-stamped histogram of the equipment activities indicating idle/busy states. Figure 3 shows a snapshot of the deigned GUI in this research.

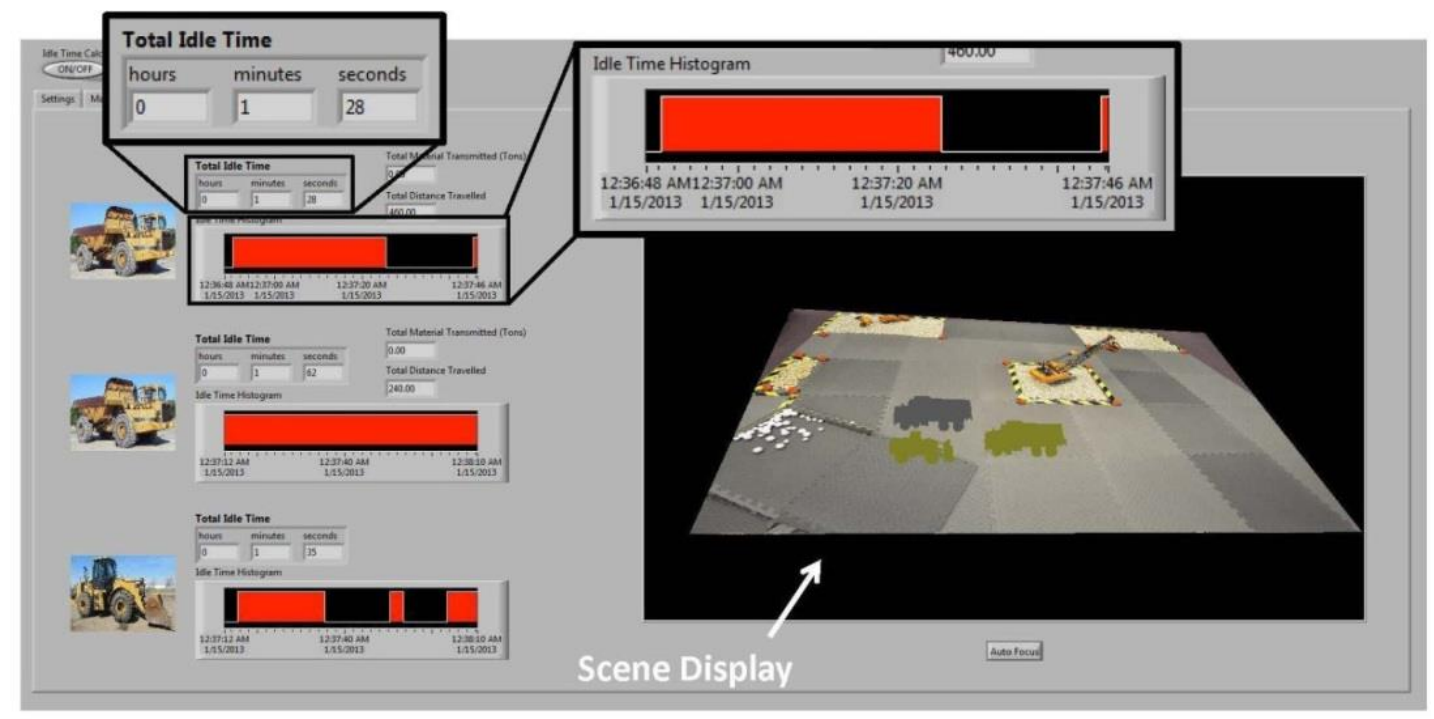

Figure 3. Snapshot of the developed GUI for equipment idle time analysis.

Although the developed system is intended for real time monitoring and decision making, a "record and play back" option is also included so that users can launch the application for training or diagnosis purposes at a time of their choice. The operation can be partially or completely recorded and played back in case further analysis is needed to identify and isolate the real causes of operational delay and locations where the equipment remained idle for extended periods of times. In addition, the user is provided with functionality to zoom in an out, change the viewing angle, modify the scale of equipment models, and other common tools that facilitate the use of the scene display. Idle time notifications and alerts are sent by a communication modules as email alerts to selected participants (e.g. fleet manager, equipment operator, site manager).

\section{IMPACT OF IDLE TIME REDUCTION ON FUEL USE AND $\mathrm{CO}_{2}$ EMISSION}

The two most popular emission inventory models that have been widely used for several years for estimating nonroad vehicle emissions, namely EPA NONROAD and California Air Resources Board (CARB) OFFROAD, do not consider equipment states for estimating fuel use (Rasdorf et al. 2010). Recently, in an attempt to quantitatively evaluate the impact of idling on fuel use and $\mathrm{CO}_{2}$ emissions of nonroad diesel construction equipment, Lewis et al. (2011) proposed a mathematical model based on operational efficiency, as defined by Equation (1): 


\section{Akhavian and Behzadan}

$$
\eta=\frac{\text { Busy Time }}{\text { Busy Time+Idle Time }}
$$

In this Equation, $\eta$ is the operational efficiency. In order to derive this generic model for backhoes, bulldozers, excavators, motor graders, off-road trucks, track loaders, and wheel loaders, emission data were collected by conducting a field study by researchers at North Carolina State University (Rasdorf et al. 2010). The result was summarized in form of Equation (2) below,

$$
N_{E}=-0.41 \ln (\eta)-0.03
$$

where $N_{E}$ is the additional fuel used at a specified operational efficiency. This is equal to the percentage difference of the fuel use at a certain reduced operational efficiency and that used at the maximum $(100 \%)$ operational efficiency. When compared to the real data collected from the filed study, the proposed model had a coefficient of accuracy of 0.85 (Lewis et al. 2011). Since approximately $99 \%$ of the carbon in diesel fuel is emitted in form of $\mathrm{CO}_{2}$, fuel use is highly correlated to $\mathrm{CO}_{2}$ emission (EPA 2005). Therefore, using this model, the resulting reduction in fuel use and $\mathrm{CO}_{2}$ emission due to a reduction in idle time of equipment can be easily quantified.

\section{SIMULATION-BASED EVALUATION}

In this Section, a case study is presented to demonstrate the impact of different operational policies on equipment idle time and consequently, operational efficiency and the $\mathrm{N}_{\mathrm{E}}$ parameter defined in Section 6. This case study was observed in Ioannou and Martinez (1996) which was presented at the 1996 Winter Simulation Conference (WSC). The problem describes a complex earthmoving operation for dam construction in which detailed engineering calculations under various stochastic conditions are needed. Therefore, in order for the decision-maker to choose between different operational strategies and plans, DES models were developed in Stroboscope, an open source simulation language designed for construction operations (Martinez 1996).

A detailed description of the problem including characteristics of different fleet models and other variables used inside the model can be found in the original paper by Ioannou and Martinez (1996). In a nutshell, a total of three front-end loaders (two CAT 936E and one CAT 950E loaders) and eleven dump trucks (eight CAT 769C and three CAT 773B trucks) are used to move 200,000 $\mathrm{m}^{3}$ of soil. Two types of heavy front-end loaders put soil into two types of heavy dump trucks at the borrow area and haul the soil to dam embankment, dump the soil, and return empty. For the hauling route which passes over a river, there are two types of temporary bridges to choose from. Type I bridge costs $\$ 95,000$ and Type II ridge costs $\$ 165,000$. However, only one dump truck is allowed to pass over Type I bridge at a time, whereas in Type II, up to six dump trucks can simultaneously travel over the bridge (but all must travel in the same direction).

This bridge decision problem opens up discussion for a sustainability analysis based on the idle times that occur not only due to waiting periods in loading and unloading activities (i.e. duty cycle modes) which can as well be the case in any typical earthmoving, but also as a result of extended waiting (and queue forming) for passing the bridge (in this specific earthmoving scenario).

Two simulation models were developed in Stroboscope to calculate the operational efficiency and $\mathrm{N}_{\mathrm{E}}$ of the heavy equipment using each bridge type. The activity cycle diagram (ACD) of the corresponding DES model is shown in Figure 4. A detailed description of the ACD elements is presented in Ioannou and Martinez (1996). In addition, the total cost of the project considering the rental price of each equipment model and the cost of the bridge, as well as total working time, and the productivity rate defined as the total soil moved per hour were calculated in each model. For each bridge type, a detailed sensitivity analysis was performed on the model and number of dump trucks. 


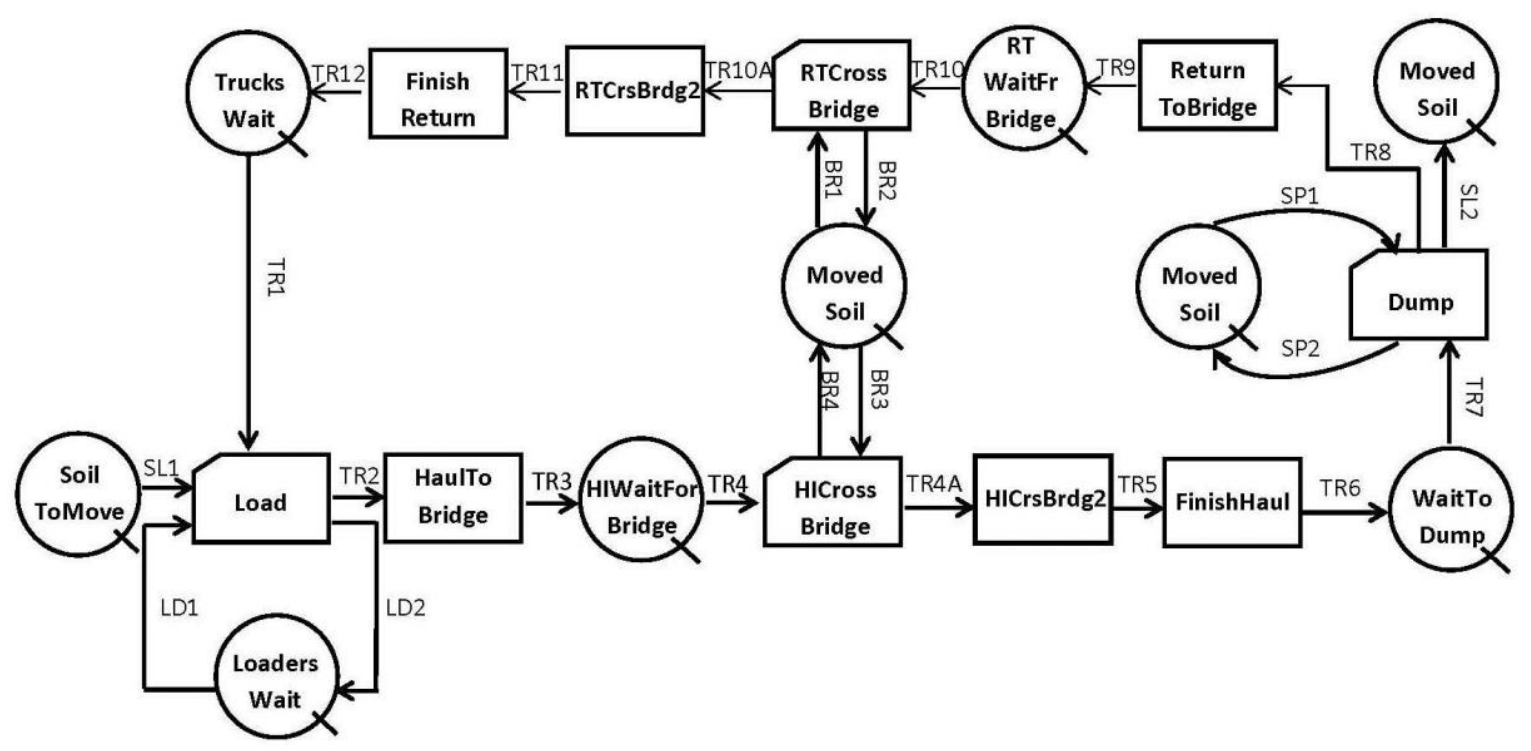

Figure 4. Activity Cycle Diagram (ACD) of the earthmoving simulation model.

Table 1 shows the result of the sensitivity analysis. As shown in this Table, Type II bridge generally outperforms Type I with regards to all the measures. Clearly, as the average idle time decreases when using different number of dump trucks or switching from Type I bridge to Type II, the operational efficiency increases and as a result, $\mathrm{N}_{\mathrm{E}}$ decreases. However, for both bridge types, while the productivity rate and total project cost increase as the dump truck combination changes, the idle time decreases in case of Type I bridge and increases in case of Type II bridge. Therefore, the tabulated simulation results are counterintuitive and the final decision about employing any of the above scenarios depends on the priorities of the project.

Table 1: DES output of earthmoving operations using two bridge types.

\begin{tabular}{|c|c|c|c|c|c|c|c|}
\hline \multirow{2}{*}{$\begin{array}{c}\text { Bridge } \\
\text { Type }\end{array}$} & \multicolumn{2}{|c|}{$\begin{array}{c}\text { Number of } \\
\text { Dump Trucks }\end{array}$} & \multirow{2}{*}{$\begin{array}{l}\text { Average } \\
\text { Idle Time } \\
\text { (Hr/Cycle) }\end{array}$} & \multirow{2}{*}{$\begin{array}{c}\text { Operational } \\
\text { Efficiency }\end{array}$} & \multirow{2}{*}{$N_{E}$} & \multirow{2}{*}{$\begin{array}{c}\text { Total Project } \\
\text { Cost (\$) }\end{array}$} & \multirow{2}{*}{$\begin{array}{l}\text { Productivity } \\
\text { Rate }\left(\mathrm{Kg} / \mathrm{m}^{3}\right)\end{array}$} \\
\hline & $\begin{array}{l}C A T \\
769 C\end{array}$ & $\begin{array}{l}C A T \\
773 B\end{array}$ & & & & & \\
\hline \multirow{4}{*}{ I } & 8 & 3 & 0.39738671 & 0.32255400 & 0.433909 & 803205.19 & 455.5177 \\
\hline & 6 & 5 & 0.37853496 & 0.34436963 & 0.407076 & 807348.28 & 485.4367 \\
\hline & 4 & 7 & 0.35854668 & 0.36826385 & 0.379572 & 809292.06 & 516.5954 \\
\hline & 3 & 8 & 0.34893486 & 0.38006273 & 0.366642 & 809323.69 & 532.8117 \\
\hline \multirow{4}{*}{ II } & 8 & 3 & 0.12170867 & 0.60726164 & 0.174506 & 634989.50 & 686.3983 \\
\hline & 6 & 5 & 0.13494915 & 0.59422772 & 0.183402 & 665968.41 & 690.2631 \\
\hline & 4 & 7 & 0.15013248 & 0.58035115 & 0.193090 & 697541.08 & 692.9043 \\
\hline & 3 & 8 & 0.15787337 & 0.57411081 & 0.197522 & 713340.58 & 694.0942 \\
\hline
\end{tabular}




\section{Akhavian and Behzadan}

The designed framework was validated by conducting a series of proof-of-concept experiments in the Decision Support, Information Modeling, and Automation Laboratory (DESIMAL) at the University of Central Florida (UCF). In each experiment, construction equipment models equipped with UWB tags, weight sensors, and AHRS trackers transmitted raw data to a central data collection unit. Figure 5 shows the setup of the experiments as well as the types of sensors mounted on equipment models. As shown in this Figure, one front-end loader was tasked with putting soil in three dump trucks. A reasoning process similar to the one described in Figure 2 was used to determine the state of equipment at any given time. The result was visualized in the developed GUI where color-coding was used to mark idle and busy equipment states. In designed experiments, an earthmoving operation was modeled in which a front-end loader was tasked with putting soil in three dump trucks that then hauled the soil to a designated dumping area and returned to the loading area (to complete an equipment cycle). Results obtained from these experiments estimated that on average, dump trucks were idle 2.14 minutes in a 3.90 minute cycle. This large amount of idle time was mainly due to the fact that dump trucks had to wait in a queue to be loaded since there was only one front-end loader available. Also, a rest/service area was considered for dump trucks in which they remained idle for a certain amount of time. The operational efficiency in this case was calculated to be about $45 \%$. Considering Equation (2), if operational efficiency is increased to $55 \%$ by reducing the idle time by 23 seconds per cycle, the hourly fuel use and $\mathrm{CO}_{2}$ emission will be reduced by approximately $8.2 \%$, as calculated by Equation (3),

$$
N_{E(0.45)}-N_{E(0.55)}=0.297-0.215=0.082=8.2 \%
$$

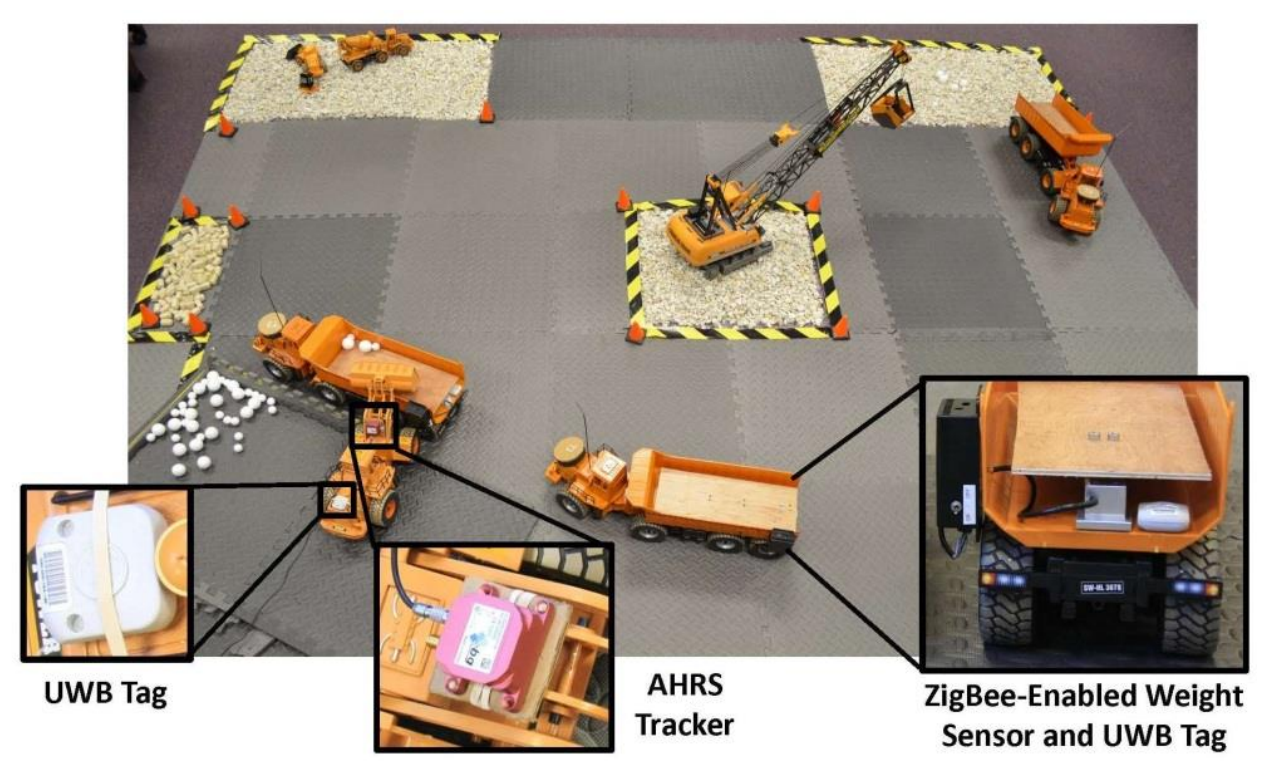

Figure 5. Setup of laboratory experiments and sensors mounted on equipment models.

\section{CONCLUSIONS AND FUTURE WORK}

Several factors contribute to the cost and energy consumption in construction projects. Costs associated with heavy equipment rental or ownership, operating and maintenance, material procurement, delivery, installation, and labor play significant roles in a contractor's overall cash flow and project productivity assessment. Similarly, actively monitoring fuel consumption of construction equipment not only can have a significant positive impact on the operating cost, but it also contributes to the prospect of a cleaner and more sustainable environment. Hence, equipment idle time reduction can be a promising solution with 


\section{Akhavian and Behzadan}

major benefits to cost and energy management problems within the construction industry. In addition to environmental benefits, cost savings associated with this reduction in fuel consumption, and less engine wear and maintenance are among several other potential advantages of idle time reduction. In an attempt to monitor the idle time of construction equipment and identify reasons why and when such idling occurs, this paper described a framework for real time monitoring of construction equipment idle times. A distributed network of sensors was deployed to collect operational data from construction equipment and send this data to a central data processing unit. Raw data were then fused and fed into a reasoning process to determine the binary idle/busy state of equipment. Time intervals during which equipment was idle were calculated in real time, and results were color-coded and visually displayed in a GUI. If the userdefined threshold for idle time was exceeded, the color of the equipment would change, and notifications would be sent to key personnel indicating that an action was needed to resolve the situation. Using the developed system, construction site managers can also record equipment activities for future analysis and determine why and when equipment went idle. This feature helps design and employ customized idling reduction strategies. As a motivating test case, DES modeling of a complex earthmoving operation coupled with a detailed sensitivity analysis showed the impact of idling reduction on the operational efficiency and other project performance measures.

Future work on this study will consider the effect of construction equipment activity duty cycles on fuel use. In other words, the busy state of equipment will be further broken down to several individual activities (e.g. loading, dumping, hauling, scooping) each resulting in different emission values of air pollutants. Furthermore, the effect of load factor which is currently simplified by the EPA (2010) through the use of a constant for different weight values can be investigated in more detail. Data-driven DES models will then be built to accept input from field processes in order to provide more realistic estimations of construction equipment emission rates in different activity cycles.

\section{ACKNOWLEDGMENTS}

The presented work has been partially supported by Bentley Systems, Inc. The authors gratefully acknowledge the support from the Bentley Systems and would especially like to thank Mr. Dean Bowman (Research Director at Bentley Systems) for his input on the development and validation of the GUI. The components of the distributed sensor network were obtained using a generous grant from the UCF Office of Research and Commercialization (ORC). Any opinions, findings, conclusions, and recommendations expressed in this paper are those of the authors and do not necessarily reflect the views of Bentley Systems, UCF, or the individual named above.

\section{REFERENCES}

Ahn, C. R., and Lee, S. 2013. "Importance of Operational Efficiency to Achieve Energy Efficiency and Exhaust Emission Reduction of Construction Operations." Journal of Construction Engineering and Management, 139(4): 404-413.

Ahn, C. R., Lee, S., and Peña-Mora, F. 2012. "Monitoring System for Operational Efficiency and Environmental Performance of Construction Operations, Using Vibration Signal Analysis." In Construction Research Congress 2012, Edited by 21-23.

Akhavian, R., and Behzadan, A. H. 2012. "An Integrated Data Collection and Analysis Framework for Remote Monitoring and Planning of Construction Operations." Advanced Engineering Informatics, 26(4): 749-761.

EPA. 2005. Average Carbon Dioxide Emissions Resulting from Gasoline and Diesel Fuel. Accessed January 14, 2013. http://www.na.chargepoint.com/UI/downloads/help/420f05001.pdf.

EPA. 2006. Model State Idling Law. Accessed January 12, 2013. http://www.epa.gov/smartway/documents/publications/420s06001.pdf.

EPA. 2008. Quantifying Greenhouse Gas Emissions in Key Industrial Sectors. Accessed January 11, 2013. http://www.epa.gov/sectors/pdf/2008/2008-sector-report-508-full.pdf. 


\section{Akhavian and Behzadan}

EPA. 2009. "Potential of Reducing Greenhouse Gas Emissions in the Construction Sector." EPA Sector Strategies Program, Washington, DC.

EPA. 2010. Exhaust and Crankcase Emission Factors for Nonroad Engine Modeling: Compression$\begin{array}{llll}\text { Ignition. } & \text { Accessed } & \text { January } & \end{array}$ http://www.epa.gov/otaq//models/nonrdmdl/nonrdmdl2010/420r10018.pdf.

Frey, H., Kuo, P. Y., and Villa, C. 2008. "Methodology for Characterization of Long-Haul Truck Idling Activity Under Real-World Conditions." Transportation Research Part D: Transport and Environment, 13(8): 516-523.

Frey, H. C., Kuo, P. Y., and Villa, C. 2009. "Effects of Idle Reduction Technologies on Real World Fuel Use and Exhaust Emissions of Idling Long-Haul Trucks." Environmental Science \& Technology, 43(17): 6875-6881.

Ioannou, P. G., and Martinez, J. C. 1996. "Simulation of Complex Construction Processes." In Proceedings of the 28th Conference on Winter Simulation, Edited by D. M. J. Charnes, D. Brunner, and J. Swain, 1321-1328. Piscataway, New Jersey: Institute of Electrical and Electronics Engineers, Inc.

Lewis, M. P. 2009. "Estimating Fuel Use and Emission Rates of Nonroad Diesel Construction Equipment Performing Representative Duty Cycles." Ph.D. Thesis, North Carolina State University, Raleigh, North Carolina.

Lewis, P., Leming, M., and Rasdorf, W. 2011. "Impact of Engine Idling on Fuel Use and CO 2 Emissions of Nonroad Diesel Construction Equipment." Journal of Management in Engineering, 28(1): 31-38.

Lewis, P., Rasdorf, W., Frey, H. C., Pang, S. H., and Kim, K. 2009. "Requirements and Incentives for Reducing Construction Vehicle Emissions and Comparison of Nonroad Diesel Engine Emissions Data Sources." Journal of Construction Engineering and Management, 135(5): 341-351.

Lim, H. 2002. Study of Exhaust Emissions from Idling Heavy-Duty Diesel Trucks and Commercially Available Idle-Reducing Devices. Accessed January 11, 2013. http://www.epa.gov/smartway/documents/publications/epaidlingtesting.pdf.

Martinez, J. C. 1996. "Stroboscope : State and Resource Based Simulation of Construction Processes." Ph.D. thesis, University of Michigan, Ann Arbour, MI.

McCahill, D. F., and Bernold, L. E. 1993. "Resource-Oriented Modeling and Simulation in Construction." Journal of Construction Engineering and Management, 119(3): 590-606.

Peña-Mora, F., Ahn, C., Golparvar-Fard, M., Hajibabai, L., Shiftehfar, S., An, S., Aziz, Z., and Song, S. 2009. "A Framework for Managing Emissions During Construction." In Proceedings of the NSF International Workshop on Green Buildings and Sustainable Construction, Edited by NSF, Cairo, Egypt: National Science Foundation.

Rasdorf, W., Frey, C., Lewis, P., Kim, K., Pang, S. H., and Abolhassani, S. 2010. "Field Procedures for Real-World Measurements of Emissions from Diesel Construction Vehicles." Journal of Infrastructure Systems, 16(3): 216-225.

Vorster, M. C., and de la Garza, J. M. 1990. "Consequential Equipment Costs Associated with Lack of Availability and Downtime." Journal of Construction Engineering and Management, 116(4): 656669.

\section{AUTHOR BIOGRAPHIES}

REZA AKHAVIAN is a Ph.D. student of Construction Engineering at the University of Central Florida (UCF). He received his Master's degree in Civil Engineering in 2012 from the same university. He also holds a B.Sc. degree in Civil Engineering from University of Tehran (Iran). His current research interests include data-driven simulation and visualization, field data collection and fusion, and data mining. He is a student member of the American Society of Civil Engineers (ASCE). His email address is reza@knights.ucf.edu and his web page is https://sites.google.com/site/rezaakhavian/. 
AMIR H. BEHZADAN is a Wharton Smith Faculty Fellow and Assistant Professor of Construction Engineering at the University of Central Florida (UCF). He received his Ph.D. in Civil Engineering in 2008 and his Master's degree in Construction Engineering and Management in 2005 both from the University of Michigan, Ann Arbor. He also holds a B.Eng. degree in Civil Engineering from Sharif University of Technology (Tehran, Iran). His current research interests include intelligent and autonomous construction systems, data-driven simulation and visualization, and construction process data mining. He is a member of the American Society of Civil Engineers (ASCE) and the Construction Industry Institute (CII), and serves on the editorial board of the ASCE Journal of Construction Engineering and Management. His email address is amir.behzadan@ucf.edu and his web page is http://pegasus.cc.ucf.edu/ abehzada/. 